\title{
Large Vulvar Lipoma in an Adolescent
}

\author{
R.K. Maurya, M.S., Pawan Singh, M.S., Sandeep Singh, M.B. \\ Department of Surgery, G.S.V.M. Medical College, Kanpur (UP), India
}

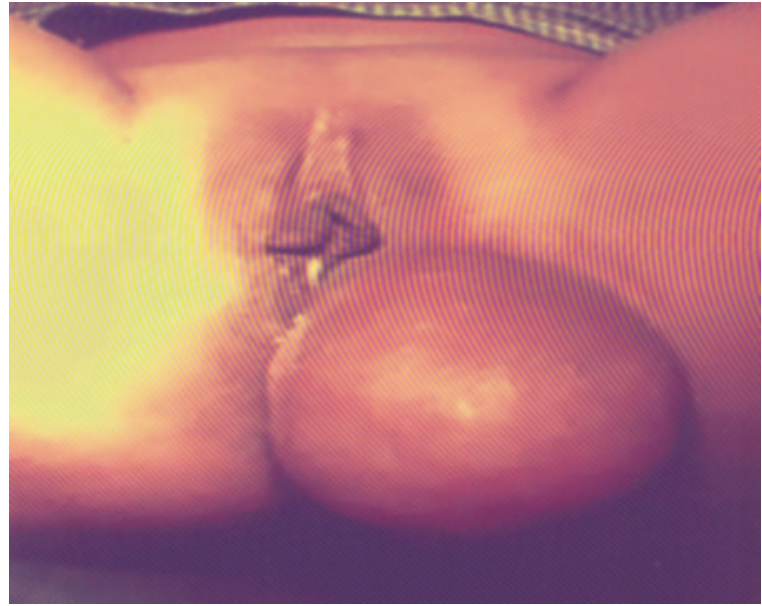

FIGURE 1. Mass on the right labia majora

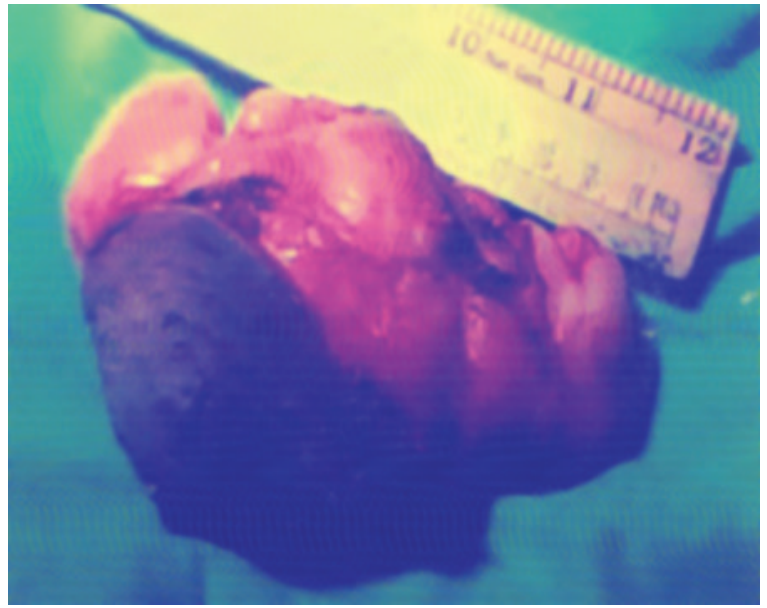

FIGURE 2. Large lipomatous mass measuring $8.2 \times 5.5 \times 3.8 \mathrm{~cm}$
Lipomas of vulva have been reported only rarely. Benign tumors of the vulva are normally classified according to their origin as epithelial cell tumors (e.g., keratinocytic, adnexal and ectopic tumors), or mesenchymal cell tumors (e.g., vascular, fibrous, muscular, neural, adipose and melanocytic tumors). Vulvar lipomas need to be differentiated from liposarcomas, which are rare but are very similar to lipomas clinically. Here we present clinical images (Figures 1 $\& 2$ ) of a rare case of large vulvar lipoma in an adolescent girl that was published in an earlier issue of JMS.

\section{Correspondence:}

Dr. R. K. Maurya

Assistant Professor,

Department of Surgery, G.S.V.M. Medical College,

Kanpur, U.P, India

E-Mail: drrajeshpuru2007@rediffmail.com

\section{References}

1. Agarwal U, Dahiya P, Sangwan K. Vulval lipoma: a rare occurrence. Arch Gynecol Obstet 2004; 270: 59-60.

2. JH Lee and SM Chung. Large vulval lipoma in an adolescent.J Korean Med Sci 2008; 23: 744-6.

3. Maurya RK, Singh P, Singh S. Large Vulvar Lipoma in an Adolescent.JMS 2011;14(1):28-29.

\section{Corrigendum}

This case report was published in the Jan-Jun 2011 issue Journal of Medical Sciences (JMS 2011;14(1):28-29). Some photographs, missing in the original case report, are being published here as clinical images. The Editorial team deeply regrets this lapse and also the sub-optimal quality of the images. 